\title{
Development and Validation of a Stability Indicating LC Method for the Assay and Related Substances Determination of a Proteasome Inhibitor Bortezomib
}

\author{
Kasa Srinivasulu, ${ }^{1,2}$ Mopidevi Narasimha Naidu, ${ }^{1}$ Kadaboina Rajasekhar, ${ }^{1}$ \\ Murki Veerender, ${ }^{1}$ and Mulukutla Venkata Suryanarayana ${ }^{2,3}$ \\ ${ }^{1}$ Active Pharmaceutical Ingredients, Dr. Reddy's Laboratories Ltd., IPDO, Bachupally, Hyderabad 500072, Andhra Pradesh, India \\ ${ }^{2}$ Department of Chemistry, Osmania University, Hyderabad 500072, Andhra Pradesh, India \\ ${ }^{3}$ Matrix Laboratories Limited, Plot 34 A, Anrich Industrial Estate, Bollaram, Medak District, Jinnaram, Mandal 502 32, \\ Andhra Pradesh, India \\ Correspondence should be addressed to Kasa Srinivasulu, kasas82003@yahoo.co.in
}

Received 24 February 2012; Accepted 10 May 2012

Academic Editor: Esther Turiel

Copyright (๑) 2012 Kasa Srinivasulu et al. This is an open access article distributed under the Creative Commons Attribution License, which permits unrestricted use, distribution, and reproduction in any medium, provided the original work is properly cited.

A novel, simple, sensitive, stability indicating HPLC method was developed and validated for quantification of impurities (process related and degradants) and assay determination of bortezomib. Stability indicating power of the method was established by forced degradation experiments and mass balance study. The chromatographic separation was achieved with Waters SymmetryShield RP18 column using gradient elution using the mobile phase-A consists of a mixture of water-acetonitrile-formic acid (715:285: 1 , $\mathrm{v} / \mathrm{v} / \mathrm{v})$ and the mobile phase-B consists a mixture of methanol-water-formic acid $(800: 200: 1, \mathrm{v} / \mathrm{v} / \mathrm{v})$, respectively. The developed method is validated for parameters like precision, accuracy, linearity, LOD, LOQ, and ruggedness. Central composite experimental design (CCD) was applied to check the robustness of the method. The stability tests were also performed on drug substances as per ICH norms.

\section{Introduction}

Bortezomib [(1R)-3-methyl-1-[[(2S)-1-oxo-3-phenyl-2-[(pyrazinylcarbonyl)amino] propyl] amino] butyl] boronic acid] is a potent first-in-class dipeptidyl boronic acid proteasome inhibitor [1-6] that was approved in May 2003 in the United States for the treatment of patients with relapsed multiple myeloma where the disease is refractory to conventional lines of therapy. Bortezomib, formerly known as PS-341 [1], bortezomib binds the proteasome via the boronic acid moiety, and therefore, the presence of this moiety is necessary to achieve proteasome inhibition. The proteasome is an interesting new target for cancer therapy, and the proteasome inhibitor PS-341 warrants continued investigation in cancer therapy. One of the potential therapeutic applications of bortezomib is an anticancer agent.

No LC methods were reported in major pharmacopeias like USP, EP, JP, and BP. A few publications are available for bortezomib, some of are available on $[7,8]$ stability and characterization of bortezomib and metabolites observed in human plasma with the help of MDS sciex API 3000 triple quadruple LC MS using turbo ion spray interface set at $325 \mathrm{C}$ and [9] enhanced delivery of cisplatin to international ovarian carcinomas mediated by the effects of bortezomib on human copper transporter and [10] one of it is in human plasma using LC MS. Extensive literature survey reveals there is no stability-indicating LC method for determination of related substances and for quantitative estimation of bortezomib in bulk drugs. An exhaustive study on the stability of bortezomib is demanding as the current International Conference on Harmonisation (ICH) guidelines require that stability analysis should be done by using stability-indicating methods, developed, and validated after stress testing on the drug under a variety of conditions, including hydrolysis (at various $\mathrm{pH}$ ), oxidation, photolysis, 
and thermal degradation [11-15]. Moreover, the structural characterization and synthesis of the degradation products allow both to establish the degradation pathways and also their quantitative determination in drug substance. Hence, in the present work, the chemical degradation pathways of bortezomib were established through a forced degradation study and a selective, precise, and accurate LC method for simultaneous estimation of bortezomib and its degradation products was also developed. The validation of the proposed method was also carried out and its applicability was evaluated in commercial form analysis.

\section{Experimental}

2.1. Chemicals and Reagents. Methanol HPLC grade and acetonitrile HPLC grade were purchased from Rankem. Formic acid, sodium hydroxide, hydrochloric acid, and hydrogen peroxide was purchased from Merck. HPLC grade water was obtained from Milli-Q water purification system (Millipore, Milford, USA).

Bortezomib drug substance, reference standard, and nine impurities were obtained from Process Research Department of Dr.Reddy's Laboratories, Hyderabad.

\subsection{Chemical Names for Bortezomib and Its Impurities}

(a) Bortezomib. [(1R)-3-methyl-1-[[(2S)-1-oxo-3-phenyl2-[(pyrazinylcarbonyl)amino]propyl] amino]butyl]boronic acid.

(b) Imp-A. Pyrazine-2-carboxylic acid (1-carbamoyl-2-phenyl-ethyl)-amide.

(c) Imp-B. (S)-3-Phenyl-2-[(pyrazine-2-carbonyl)-amino]propionic acid.

(d) Imp-C. 1-[[(2S)-1-oxo-3-phenyl-2-[(pyrazinylcarbonyl) amino]propyl]amino] pentylboronic acid.

(e) Imp-D. [(1R)-3-methyl-1-(\{(2R)-3-phenyl-2-[(pyrazin2-ylcarbonyl)amino]propanoyl $\}$ amino)butyl]boronic acid. (or) [(1S)-3-methyl-1-(\{(2S)-3-phenyl-2-[(pyrazin-2-ylcarbonyl)amino] propanoyl\}amino)butyl]boronic acid.

(f) Imp-E. Pyrazine-2-carboxylic acid [1-(1-hydroxy-3-methyl-butylcarbamoyl)-2-phenyl-ethyl]-amide.

(g) Imp-F. (S)-3-Phenyl-2-[(pyrazine-2-carbonyl)-amino]propionic acid methylester.

(h) Imp-G. Pyrazine-2-carboxylic acid [1-(1-hydroxy-3methyl-butylcarbamoyl)-2-phenyl-ethyl]-amide.

(i) Imp-H. Pyrazine-2-carboxylic acid [1-(3-methyl-butylcarbamoyl)-2-phenyl-ethyl]-amide. (j) Imp-I. Pyrazine-2-carboxylic acid \{1-[3-methyl-1-(2,9, 9-trimethyl-3,5-dioxa-4-bora-tricyclo [6.1.1.02,6] dec-4-yl)butylcarbamoyl]-2-phenyl-ethyl\}-amide.

The structures of Imp-A, Imp-B, Imp-C, Imp-D, Imp-E, Imp-F, Imp-G, Imp-H, Imp-I, and bortezomib were shown in (Figure 1).

2.3. Instrumentation and Software. Two LC system were used for method development and validation.

LC 1: Waters make (2695 separation module and a PDA detector 996) with empower software.

LC 2: Waters make (2695 separation module and a 2487 Dual $\lambda$ Absorbance detector) with empower software.

2.4. Chromatographic Conditions. The method was developed using Waters SymmetryShield RP18 $5 \mu \mathrm{m}, 4.6 \times 250 \mathrm{~mm}$ column (Waters, Milford, USA) with mobile phase containing a gradient mixture of mobile phase $\mathrm{A}$ and $\mathrm{B}$. Mobile phase-A consists a mixture of water-acetonitrile-formic acid $(715: 285: 1, \mathrm{v} / \mathrm{v} / \mathrm{v})$ and the mobile phase-B consists a mixture of methanol-water-formic acid $(800: 200: 1, \mathrm{v} / \mathrm{v} / \mathrm{v})$, respectively. Exact composition of mobile phase-A preparation is required to achieve resolution between bortezomib and Imp-C $(R s>3.0)$. The gradient program $(\mathrm{T} / \% \mathrm{~B})$ was set as $0 / 0,20.0 / 0,35.0 / 100,50.0 / 100,52.0 / 0$, and 60.0/0. The mobile phase was filtered through a nylon $0.45 \mu \mathrm{m}$ membrane filter. The flow rate of the mobile phase was $1.0 \mathrm{~mL} / \mathrm{min}$. The column temperature was maintained at $35^{\circ} \mathrm{C}$ and the wavelength was monitored at $270 \mathrm{~nm}$. The injection volume was $10 \mu \mathrm{L}$. A mixture of acetonitrile-water $(7.5: 17.5, \mathrm{v} / \mathrm{v})$ was used as diluent.

2.5. LC-MS/MS Conditions. LC-MS/MS system (Waters 2695 Alliance liquid chromatograph coupled with quattromicro-mass spectrometer with Mass Lynx software, Waters Corporation, Milford, USA) was used for the unknown compounds formed during forced degradation studies. Waters SymmetryShield RP18 $5 \mu \mathrm{m}, 4.6 \times 250 \mathrm{~mm}$ column (Waters, Milford, USA) was used as stationary phase. Mobile phase-A consists a mixture of water-acetonitrile-formic acid $(715: 285: 1, v / v / v)$ and the mobile phase-B consists a mixture of methanol-water-formic acid $(800: 200: 1, \mathrm{v} / \mathrm{v} / \mathrm{v})$ respectively. The gradient program $(\mathrm{T} / \% \mathrm{~B})$ was set as $0 / 0$, $20.0 / 0,35.0 / 100,50.0 / 100,52.0 / 0$ and $60.0 / 0$. The flow rate was $1.0 \mathrm{~mL} / \mathrm{min}$. The analysis was performed in positive electro spray positive ionization mode.

The analysis was performed in positive electro spray positive ionization mode. Capillary and cone voltages were $3.5 \mathrm{kV}$ and $25 \mathrm{~V}$, respectively. Source and dissolution temperatures were 120 and $350^{\circ} \mathrm{C}$, respectively. Dissolution gas flow was $650 \mathrm{Lh}^{-1}$.

2.6. Preparation of Standard Solutions. A stock solution of bortezomib standard as well as sample was prepared at $1000 \mu \mathrm{g} / \mathrm{mL}$ for analysis of related substances and for assay determination. A stock solution of impurities (mixture of 
<smiles>CC(C)C[C@H](NC(=O)[C@H](Cc1ccccc1)NC(=O)c1cnccn1)B(O)O</smiles>

Bortezomib<smiles>CCCCC(NC(=O)[C@H](Cc1ccccc1)NC(=O)c1cnccn1)B(O)O</smiles>

Imp-C<smiles>CC(C)C[C@H](O)NC(=O)[C@H](Cc1ccccc1)NC(=O)c1cnccn1</smiles>

Imp-E<smiles>CC(C)CCNC(=O)[C@H](Cc1ccccc1)NC(=O)c1cnccn1</smiles>

Imp-H<smiles>NC(=O)[C@H](Cc1ccccc1)NC(=O)c1cnccn1</smiles>

Imp-A<smiles>CC(C)C[C@H](NC(=O)[C@H](Cc1ccccc1)NC(=O)c1cnccn1)B(O)O</smiles>

$\operatorname{Imp-D}(\mathrm{R}, \mathrm{R})$<smiles>COC(=O)[C@H](Cc1ccccc1)NC(=O)c1cnccn1</smiles>

Imp-F<smiles>O=C(N[C@@H](Cc1ccccc1)C(=O)O)c1cnccn1</smiles>

Imp-B

$\operatorname{Imp}-\mathrm{D}(\mathrm{S}, \mathrm{S})$<smiles>CC(C)C[C@H](O)NC(=O)[C@H](Cc1ccccc1)NC(=O)c1cnccn1</smiles>

Imp-G<smiles>CC(C)C[C@H](NC(=O)[C@H](Cc1ccccc1)NC(=O)c1cnccn1)B1O[C@@H]2C[C@H]3C[C@H](C2(C)C)[C@]3(C)O1</smiles>

Imp-I

FIgURE 1: Structures of bortezomib and its nine impurities.

Imp-A, Imp-B, Imp-C, Imp-D, Imp-E, Imp-F, Imp-G, Imp$\mathrm{H}$, and Imp-I) at $100 \mu \mathrm{g} / \mathrm{mL}$ was also prepared in the solvent mixture.

2.7. Method Validation. The proposed method was validated as per ICH guidelines [16].

2.7.1. Solution Stability and Mobile Phase Stability. The stability of bortezomib in solution was determined by leaving test solutions of the sample and reference standard in tightly capped volumetric flasks at room temperature for $48 \mathrm{~h}$ during which they were assayed at $12 \mathrm{~h}$ intervals. Stability of mobile phase was determined by analysis of freshly prepared sample solutions at $12 \mathrm{~h}$ intervals for $48 \mathrm{~h}$ and comparing the results with those obtained from freshly prepared reference standard solutions. The mobile phase was prepared at the beginning of the study period and not changed during the experiment. The \% assay of the results was calculated for both the mobile phase and solution-stability experiments.

The stability of bortezomib and its impurities in solution for the related substance method was determined by leaving spiked sample solution in a tightly capped volumetric flask at room temperature for $48 \mathrm{~h}$ and measuring the amounts 
of the nine impurities at every $12 \mathrm{~h}$. The stability of mobile phase was also determined by analysis freshly prepared solution of bortezomib and its impurities at $12 \mathrm{~h}$ intervals for $48 \mathrm{~h}$. The mobile phase was not changed during the study period.

2.7.2. Specificity and Mass Balance Study. Specificity is the ability of the method to measure the analyte response in the presence of its potential impurities. The specificity of the developed LC method for bortezomib was carried out in the presence of its nine impurities. Stress studies were performed at an initial concentration $1000 \mu \mathrm{g} / \mathrm{mL}$ of bortezomib to provide an indication of the stability-indicating property and specificity of the proposed method.

Intentional degradation was attempted to stress condition of Photodegradation as per ICH Q2B (1.2 million lux hours and 200 watt hours/square meter) for 7 days, for thermal degradation, bortezomib was placed in a hot air oven maintained at $105^{\circ} \mathrm{C}$ for for $7 \mathrm{~h}$. The degradation in acidic condition was done in $5.0 \mathrm{~N} \mathrm{HCl}$ and the solution was left in dark at $70^{\circ} \mathrm{C}$ for $72 \mathrm{~h}$. The degradation in basic condition was done in $0.1 \mathrm{~N} \mathrm{NaOH}$ and the solution was left in dark at $25^{\circ} \mathrm{C}$ for $7 \mathrm{~h}$. To test the stability in neutral solution bortezomib was dissolved in water with cosolvent and left at $70^{\circ} \mathrm{C}$ for $72 \mathrm{~h}$.

For oxidative conditions, the degradation was done in $3.0 \%$ hydrogen peroxide solution and analyzed immediately. Before LC and LC-MS/MS analyses, acidic and alkaline samples were neutralized and diluted by adding an appropriate volume of diluent. For comparison, an aqueous solution of bortezomib $(1000 \mu \mathrm{g} / \mathrm{mL})$ was prepared, diluted, and analyzed as above.

Peak purity test was carried out for the bortezomib peak by using PDA detector in all stressed samples.

Assay of stressed samples was performed (at $1000 \mu \mathrm{g} / \mathrm{mL}$ ) by comparison with qualified reference standard and the mass balance ( $\%$ assay $+\%$ impurities $+\%$ degradation products) was calculated. Assay was also calculated for bortezomib sample by spiking all nine impurities at the specification level (i.e., $0.15 \%$ ).

2.7.3. Linearity. Linearity test solutions for the assay method were prepared from bortezomib solutions at five concentration levels from 50 to $150 \%$ of assay analyte concentration $(0.5,0.75,1.0,1.25$, and $1.50 \mathrm{mg} / \mathrm{mL})$. The peak area versus concentration data was treated by least-squares linear regression analysis. Linearity test solutions for the related substance method were prepared by diluting stock solutions to the required concentrations. The solutions were prepared at six concentration levels from LOQ to $150 \%$ of the specification level (LOQ, 0.0375, 0.075, 0.1125, 0.15, 0.1875, and 0.225\%).

2.7.4. Limits of Detection (LOD) and Quantification (LOQ). The LOD and LOQ for all nine impurities and bortezomib were estimated at a signal-to-noise ratio of $3: 1$ and $10: 1$, respectively, [17] and [18], by injecting a series of diluted solutions with known concentration. Precision study was also carried at the LOQ level by injecting six individual preparations of all nine impurities and bortezomib and calculating the \% RSD of the area. Accuracy at LOQ level was evaluated in triplicate for the nine impurities by spiking the impurities at the estimated LOQ level to test solution.

2.7.5. Accuracy. The accuracy of the assay method was evaluated in triplicate using three-concentration levels, that is, $0.5,1.0$, and $1.5 \mathrm{mg} / \mathrm{mL}$ in bulk drug sample. The $\%$ recoveries were calculated from $1.0 \mathrm{mg} / \mathrm{mL}$ of reference standard preparation.

Bulk samples received from Process Research Department of Dr. Reddy's Laboratories show the presence of Imp-A, Imp-B, Imp-C, Imp-D, Imp-E, Imp-F, Imp-G, Imp-H, and Imp-I in between $0.02 \%$ and $0.03 \%$ levels. Standard addition and recovery experiments were conducted to determine accuracy of the related substance method for the quantification of all nine impurities in bulk drug samples. The study was carried out in triplicate at $0.075 \%, 0.15 \%$, and $0.225 \% \mathrm{w} / \mathrm{w}$ of the related substances test concentration. The percentages of recoveries for bortezomib and its impurities were calculated.

2.7.6. Precision. The precision of the method verified by repeatability and by intermediate precision. Repeatability was checked by (waters make 2695 separation module and a PDA detector 996) injecting six individual preparations of bortezomib sample spiked with $0.15 \%$ of its nine impurities $(0.15 \%$ of impurities with respect to $1.0 \mathrm{mg} / \mathrm{mL}$ Bortezomib). \% RSD of content (\%) for each impurity was calculated. The intermediate precision of the method was also evaluated using different analyst and different instrument (waters make 2695 separation module and a 2487 dual $\lambda$ absorbance detector), and performing the analysis on different days.

Assay method precision was evaluated by carrying out six independent assays of sample of bortezomib at $1.0 \mathrm{mg} / \mathrm{mL}$ level against qualified reference standard. The intermediate precision of the assay method was evaluated by different analysts.

2.7.7. Robustness. As defined by the ICH, the robustness of an analytical procedure describes to its capability to remain unaffected by small and deliberate variations in method parameters [19]. In order to study the simultaneous variation of the factors on the considered responses, a multivariate approach using design of experiments is recommended in robustness testing. A response surface method was performed to obtain more information and to investigate the behavior of the response around the nominal values of the factors. Response surface methodology (RSM) has the following advantages: (a) to allow a complete study where all interaction effects are estimated and (b) to give an approximate description of an experimental region around a center of interest with validity of interpolation [20-22]. Generally, the large numbers of experiments required by standard designs applied in RSM disenchant their use in the validation procedure. However, if an analytical method is fast and requires the testing of a few factors (three or less), a good 
TABLE 1: Factors and level studied for robustness testing.

\begin{tabular}{lccc}
\hline Factors & \multicolumn{3}{c}{ Level } \\
& -1 & 0 & +1 \\
\hline (A) Flow rate (mL/min) & 0.8 & 1.0 & 1.2 \\
(B) Acetonitrile (\%) & 28.0 & 28.5 & 29.0 \\
(C) Methanol (\%) & 79.0 & 80.0 & 81.0 \\
\hline
\end{tabular}

choice for robustness testing may be the central composite design (CCD) [23], widely employed because of its high efficiency with respect to the number of runs required. In order to study the variables at no more than three levels $(-1$, $0,+1)$, the design used in robustness testing of bortezomib was a central composite design (CCD) with $\mathrm{D}= \pm 1$ [24]. Three factors were considered: flow rate $\mathrm{mL} \mathrm{min}^{-1}(\mathrm{~A})$; acetonitrile \% (B) and methanol \% (C). The factors and level considered for the study are shown in Table 1.

A precision solution was prepared by spiking the impurities Imp-A, Imp-B, Imp-C, Imp-D, Imp-E, Imp-F, Imp-G, Imp-H, and Imp-I at $0.15 \% \mathrm{w} / \mathrm{w}$ with respect to bortezomibrelated substances analysis concentration.

A standard and sample of bortezomib were prepared in assay concentration.

The critical resolution between bortezomib and Imp-C, Imp-E and Imp-F, and \% Recovery Assay of bortezomib were studied as response surface.

\section{Results and Discussion}

3.1. Method Development and Optimization. The main target of the chromatographic method is to get the separation of impurities and degradants generated, from bortezomib. It was also aimed method should be capable of resolving all impurities from each other.

Because alkyl borane compound present in bortezomib was known to be susceptible to oxidation by peroxides, it was speculated that the degradation of Bortetzomib in the presence of peroxide to form major Imp-E and a further degradation to Imp-G and Imp-A [25]. The major degradents Imp-A and Imp-B were observed during the process of basic and acidic catalyzed degradation [25].

These impurities were isolated. The possible degradents and related impurities of bortezomib are very similar to respective drug substance (Figure 1). To obtain a good resolution among the impurities and main drug substances, different stationary phases were tested considering

(a) the feature of stationary phase (RP-C $\mathrm{C}_{8}$ and $\left.\mathrm{RP}-\mathrm{C}_{18}\right)$,

(b) the particle size of the column $(3 \mu \mathrm{m}$ and $5 \mu \mathrm{m})$.

Detection was performed at $270 \mathrm{~nm}$, the $\lambda_{\max }$ of bortezomib. The anticipated degradation products as well as all related impurities were expected to absorb at this wavelength and therefore be detected.

These forced degradation samples and all impurities blend solution were injected in Trail-1. In tiral-1, mobile phase $\mathrm{A}$ is mixture of water-acetonitrile-formic acid $(500: 500: 1, \mathrm{v} / \mathrm{v} / \mathrm{v})$ and mobile phase $\mathrm{B}$ is mixture

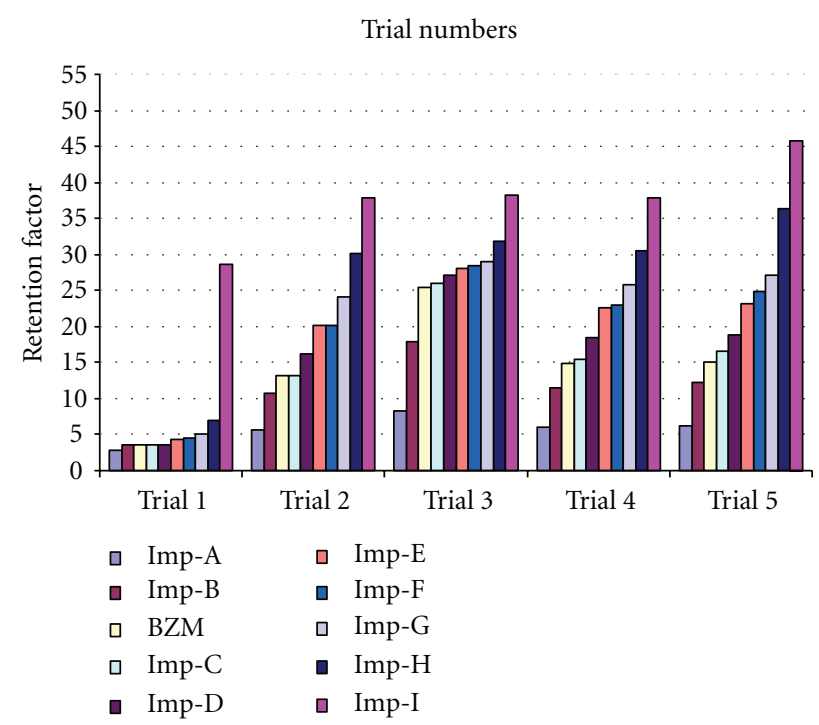

FIGURE 2: Graphical representation of retention factor of components in different trials.

of water-acetonitrile-formic acid $(500: 500: 1, \mathrm{v} / \mathrm{v} / \mathrm{v})$, column temperature was maintained at $25^{\circ} \mathrm{C}$, and all other chromatographic conditions adopted were, as described in Section 2.4. In this trial, it is observed that separation between Imp-B, Imp-C and Imp-D was coeluted with the analtye and Imp-E was coeluted with Imp-F. Attempts were given to modify the mobile phase-A and mobile phase- $\mathrm{B}$ to increase the resolution and peak symmetry.

It was decided to adopt mobile phase B as water-acetonitrile-formic acid $(200: 800: 1, \mathrm{v} / \mathrm{v} / \mathrm{v})$ and a fixed gradient program mentioned in Section 2.4 for further trials. Organic modifier (mobile phase A) was changed in each trial. The mobile phase $\mathrm{A}$ and $\mathrm{B}$ used in different trials was given in Table 2. Column temperature was kept at $35^{\circ} \mathrm{C}$ for trial 5 to reduce the back pressure and to improve the peak symmetry and in all other trials it was maintained at $25^{\circ} \mathrm{C}$.

In each trial, the forced degradation and impurity blend samples were injected. Attention was given for the separation of all nine impurities and bortezomib. Retention factor of each impurities and bortezomib obtained with each trial is presented graphically in (Figure 2).

The outcome of each trial is discussed below.

Trial 2. It was observed that the Imp-C co-eluted with bortezomib, Imp-E co-eluted with Imp-F and other impurities were separated from each other.

Trial 3. Imp-C was separated from bortezomib peak but poor resolution was observed. Apart from that, Imp-E, Imp$\mathrm{F}$, and Imp-G were very closely eluted.

Trial 4. All impurities were separated from each other and with bortezomib, the resolution between bortezomib and Imp-C $(R s>3.0)$ was increased with satisfactory result, but the resolution between Imp-E and Imp-F $(R s<1.2)$ were increased but not satisfactory. Few attempts were made 
TABLE 2

(a)

\begin{tabular}{llc}
\hline Trial Number & \multicolumn{1}{c}{ Mobile phase A } & Composition ratio of mobile phase A \\
\hline 1 & Acetonitrile: Water : Formic acid & $500: 500: 1$ \\
2 & Acetonitrile: Water : Formic acid & $300: 700: 1$ \\
3 & Acetonitrile: Water : Formic acid & $250: 750: 1$ \\
4 & Acetonitrile: Water : Formic acid & $285: 715: 1$ \\
5 & Acetonitrile: Water : Formic acid & $285: 715: 1$ \\
\hline
\end{tabular}

Mobile phase A used for different trials.

(b)

\begin{tabular}{lcc}
\hline Trial Number & Mobile phase B & Composition ratio of mobile phase B \\
\hline 1 & Acetonitrile : Water : Formic acid & $500: 500: 1$ \\
2 & Acetonitrile : Water : Formic acid & $800: 200: 1$ \\
3 & Acetonitrile : Water : Formic acid & $800: 200: 1$ \\
4 & Acetonitrile : Water : Formic acid & $800: 200: 1$ \\
5 & Methanol : Water : Formic acid & $800: 200: 1$ \\
\hline
\end{tabular}

Mobile phase B used for different trials.

to separate those critical impurities by changing the formic acid, buffers in trial-4, but there was no improvement in the resolution between Imp-E and Imp-F.

Trial 5. Result from trial-4 methanol was used as organic modifier in mobile pahse-B. Hence, this trial was conducted with methanol as organic modifier in mobile phase- $\mathrm{B}$ and column temperature was kept at $35^{\circ} \mathrm{C}$. Imp-E and Imp-F were well resolved $(R s>2.5)$.

Based on above, it was concluded that trial-5 was highly selective for the quantification of impurities, degradants as well as bortezomib. At these chromatographic conditions, all the impurities and degradants were well separated amongst and also from bortezomib. This gradient program ensured the elution of all other impurities found in crude API. The final chromatographic conditions are concluded on Waters SymmetryShield RP18 $5 \mu \mathrm{m}, 4.6 \times 250 \mathrm{~mm}$ column (Waters, Milford, USA) with mobile phase containing a gradient mixture of mobile phase A and B. Mobile phase-A consists a mixture of water-acetonitrile-formic acid (715:285:1, v/v/v) and the mobile phase-B consists a mixture of methanolwater-formic acid $(800: 200: 1, \mathrm{v} / \mathrm{v} / \mathrm{v})$, respectively. The gradient program $(\mathrm{T} / \% \mathrm{~B})$ was set as $0 / 0,20.0 / 0,35.0 / 100$, $50.0 / 100,52.0 /, 0$ and $60.0 / 0$. The mobile phase was filtered through a nylon $0.45 \mu \mathrm{m}$ membrane filter. The flow rate of the mobile phase was $1.0 \mathrm{~mL} / \mathrm{min}$. The column temperature was maintained at $35^{\circ} \mathrm{C}$ and the wavelength was monitored at $270 \mathrm{~nm}$. The injection volume was $10 \mu \mathrm{L}$. Under the above conditions, results were as follows: retention time of bortezomib was around $15.0 \mathrm{~min}$, with a tailing factor of 1.1 and $\%$ RSD for five replicate injections was $0.1 \%$. Accelerated and long-term stability study results as per ICH Q1A (R2) for bortezomib were generated for 6 months by using the developed LC method and the results were well within the limits, this further confirms the stability indicating of the method.
The typical HPLC chromatograms (Figure 3) represent the satisfactory separation of all components among each other.

\subsection{Validation of the Method}

3.2.1. Solution Stability and Mobile Phase Stability. Assay (\%) of bortezomib during solution stability and mobile phase stability experiments was within $\pm 1 \%$. The variability in the estimation of bortezomib impurities was within $\pm 10 \%$ during solution stability and mobile phase experiments when performed using the related substances method. The results from mobile phase stability experiments confirmed that standard solutions and solutions in the mobile phase were stable up to $48 \mathrm{~h}$ for assay and related substances analysis.

The results from solution stability experiments confirmed that standard solution was stable up to $48 \mathrm{~h}$ and impurities spiked test solution was stable up to $24 \mathrm{~h}$.

3.2.2. Specificity and Mass Balance Study. All forced degradation samples were analyzed at an initial concentration $1000 \mu \mathrm{g} / \mathrm{mL}$ of bortezomib with HPLC conditions mentioned in Section 2.4 using PDA detector to ensure the homogeneity and purity of bortezomib peak. Very significant degradation of bortezomib was observed in oxidative, thermal, acid and base stress conditions leading to the formation of Imp-A, Imp-B, and Imp-E (Figure 4) [25]. This was confirmed by coinjecting impurity standards to these degraded samples and by LC-MS/MS analysis. LC-MS/ MS analysis was performed as per Section 2.5. Significant degradation was observed in water hydrolysis and photolytic open stress conditions. bortezomib was found to be stable under photolytic closed stress condition.

Assay studies were carried out for stress samples (at $1000 \mu \mathrm{g} / \mathrm{mL}$ ) against bortezomib qualified reference standard. The mass balance ( $\%$ assay $+\%$ sum of all compounds $+\%$ sum of all degradants) results were calculated 


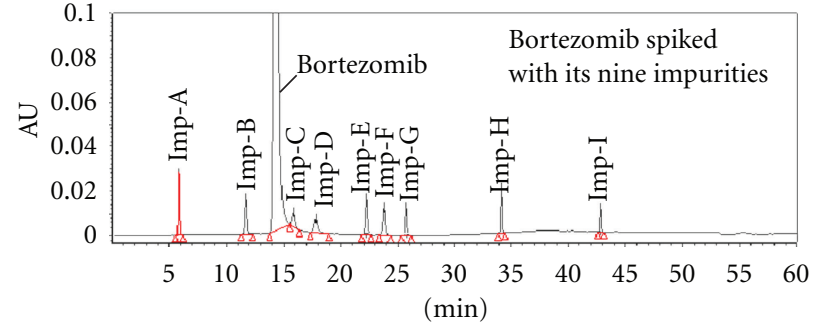

(a)

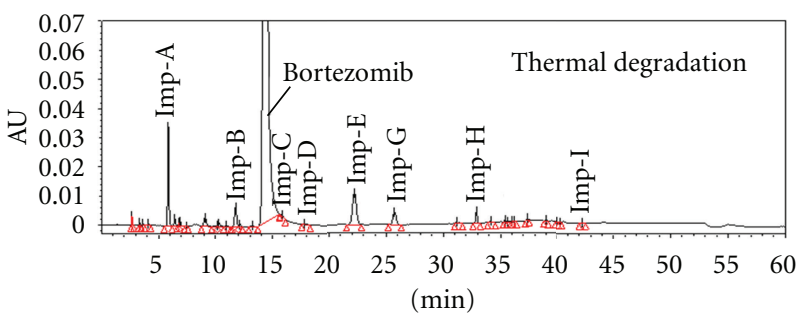

(c)

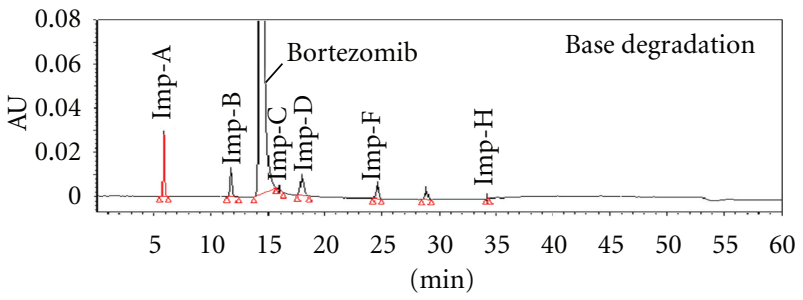

(e)

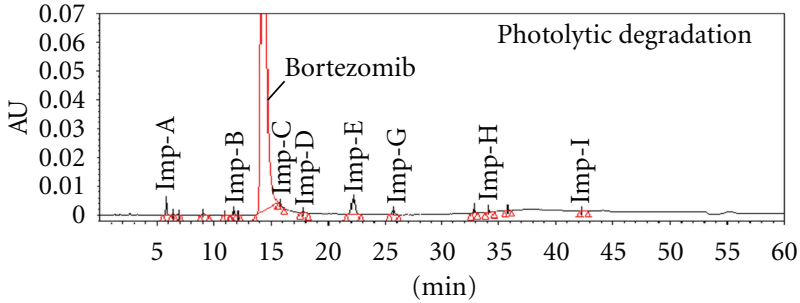

(b)

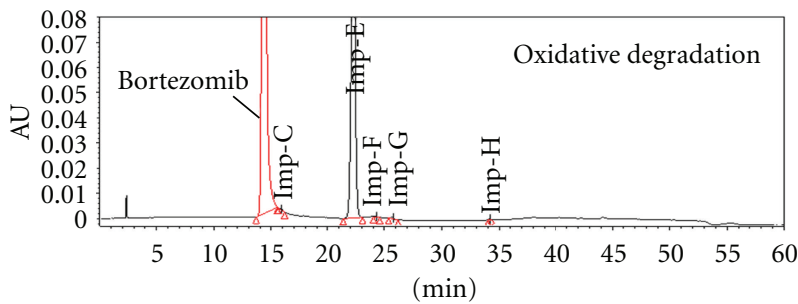

(d)

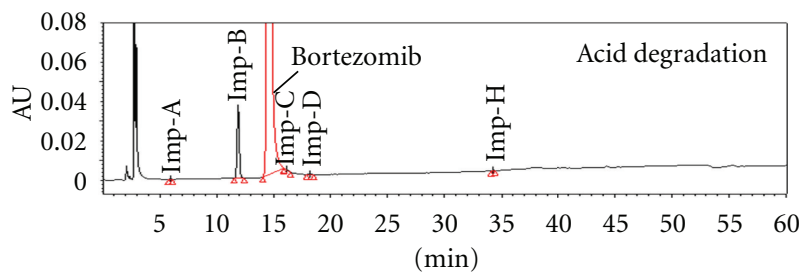

(f)

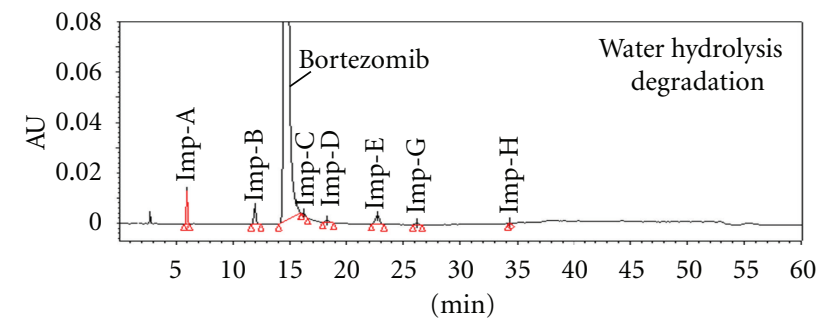

(g)

FIgURE 3: Typical chromatograms of bortezomib spiked with its nine impurities and its forced degradation samples.

for all stressed samples and found to be more than $99.2 \%$ (Table 3). The purity and assay of bortezomib was unaffected by the presence of its impurities and degradation products and thus confirms the stability-indicating power of the developed method.

3.2.3. Relative Response Factor. Relative response factor (RRF) was established for Imp-A, Imp-B, Imp-C, Imp-D, Imp-E, Imp-F, Imp-G, Imp-H, and Imp-I as the ratio of slope of impurities and slope of bortezomib. Slope value obtained with linearity calibration plot was used for RRF determination. Established RRF value for Imp-A, Imp-B, Imp-C, Imp-D, Imp-E, Imp-F, Imp-G, Imp- $\mathrm{H}$, and Imp-I are $1.41,1.45,0.92,1.00,0.94,1.37,0.97,1.09$, and 0.67 , respectively.

3.2.4. Linearity. The linearity calibration plot for the assay method was obtained over the calibration ranges tested, and correlation coefficient obtained was greater than 0.999 . The result shows that an excellent correlation existed between the peak area and concentration of the analyte.

Linear calibration plot for the related substance method was obtained over the calibration ranges tested, that is, LOQ to $150 \%$ for impurities. The correlation coefficient obtained was greater than 0.999 (Table 4). The above result shows that an excellent correlation existed between the peak area and the concentration of Imp-A, Imp-B, Imp-C, Imp-D, Imp-E, Imp-F, Imp-G, Imp-H, Imp-I, and bortezomib. The linearity established with bortezomib is applicable to unspecified impurities.

3.2.5. Limits of Detection and Quantification. The determined limit of detection, limit of quantification values for bortezomib, and its nine impurities are reported in Table 4 . The method precision for Imp-A, Imp-B, Imp-C, Imp-D, Imp-E, Imp-F, Imp-G, Imp-H, Imp-I, and bortezomib at 
<smiles>CC(C)C[C@H](NC(=O)[C@H](Cc1ccccc1)NC(=O)c1cnccn1)B(O)O</smiles><smiles>CC(C)C[C@H](O)NC(=O)[C@H](Cc1ccccc1)NC(=O)c1cnccn1</smiles>
Oxygen or peroxide

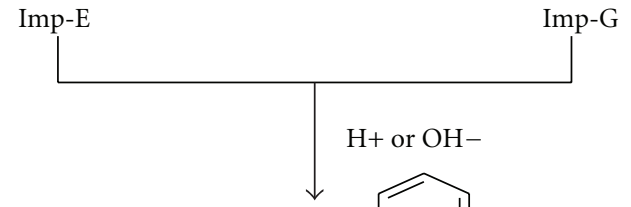<smiles>CC(C)C[C@H](O)NC(=O)[C@H](Cc1ccccc1)NC(=O)c1cnccn1</smiles><smiles>C=C/C=C(\C)C[C@H](NC(=O)c1cnccn1)C(N)=O</smiles><smiles>O[Hg+2]O</smiles>

Imp-A Imp-B

Figure 4: Degradation scheme of bortezomib; Imp-E, Imp-G, Imp-A, and Imp-B.

TABle 3: Mass balance study.

\begin{tabular}{|c|c|c|c|c|c|}
\hline Stress condition & Time & $\begin{array}{c}\text { Assay of active } \\
\text { substance }(\% \mathrm{w} / \mathrm{w})\end{array}$ & $\begin{array}{c}\text { Total impurities } \\
(\% \mathrm{w} / \mathrm{w})\end{array}$ & $\begin{array}{c}\text { Mass balance (assay }+ \text { total } \\
\text { impurities) }(\% \mathrm{w} / \mathrm{w})\end{array}$ & Remarks \\
\hline Thermal treatment $\left(105^{\circ} \mathrm{C}\right)$ & $7 \mathrm{~h}$ & 92.4 & 7.0 & 99.4 & $\begin{array}{l}\text { Imp-A, Imp-E and } \\
\text { Imp-G were major } \\
\text { degradation products }\end{array}$ \\
\hline $\begin{array}{l}\text { Photo degradation (Open } \\
\text { stress) }\end{array}$ & 7 days & 96.9 & 2.4 & 99.3 & $\begin{array}{l}\text { Imp-A, Imp-E and } \\
\text { Imp-G were major } \\
\text { degradation products }\end{array}$ \\
\hline $\begin{array}{l}\text { Acid hydrolysis }(5.0 \mathrm{M} \mathrm{HCl} \text {, } \\
\left.70^{\circ} \mathrm{C}\right)\end{array}$ & $72 \mathrm{~h}$ & 96.2 & 3.0 & 99.2 & $\begin{array}{l}\text { Imp-B was major } \\
\text { degradation product. }\end{array}$ \\
\hline $\begin{array}{l}\text { Base hydrolysis }(0.1 \mathrm{M} \\
\left.\mathrm{NaOH}, 25^{\circ} \mathrm{C}\right)\end{array}$ & $7 \mathrm{~h}$ & 94.4 & 5.3 & 99.8 & $\begin{array}{l}\text { Imp-A, Imp-B and } \\
\text { Imp-D were major } \\
\text { degradation products }\end{array}$ \\
\hline Oxidation $\left(3 \% \mathrm{H}_{2} \mathrm{O}_{2}\right)$ & Immediately & 81.9 & 17.9 & 99.8 & $\begin{array}{l}\text { Imp-E was major } \\
\text { degradation product. }\end{array}$ \\
\hline Water hydrolysis $\left(70^{\circ} \mathrm{C}\right)$ & $72 \mathrm{~h}$ & 97.4 & 2.1 & 99.5 & $\begin{array}{l}\text { Imp-A, Imp-B and } \\
\text { Imp-E were major } \\
\text { degradation products }\end{array}$ \\
\hline
\end{tabular}


TABLE 4: Regression data.

\begin{tabular}{|c|c|c|c|c|c|c|c|c|c|c|}
\hline Parameter & Bortezomib & Imp-A & Imp-B & Imp-C & Imp-D & Imp-E & Imp-F & Imp-G & Imp-H & Imp-I \\
\hline $\mathrm{LOD}(\mu \mathrm{g} / \mathrm{mL})$ & 0.043 & 0.012 & 0.025 & 0.043 & 0.043 & 0.047 & 0.038 & 0.045 & 0.024 & 0.060 \\
\hline $\operatorname{LOQ}(\mu \mathrm{g} / \mathrm{mL})$ & 0.174 & 0.048 & 0.100 & 0.173 & 0.174 & 0.188 & 0.152 & 0.179 & 0.097 & 0.239 \\
\hline $\begin{array}{l}\text { Regression equation }(y) \\
\text { Slope }(b)\end{array}$ & 13289 & 22831 & 20852 & 12009 & 13934 & 14688 & 19330 & 17640 & 15812 & 8765 \\
\hline Intercept $(a)$ & -404 & -309 & -296 & 130 & 45 & -386 & 344 & -486 & -397 & 617 \\
\hline Correlation coefficient & 0.9995 & 0.9995 & 0.9998 & 0.9993 & 0.9995 & 0.9993 & 0.9994 & 0.9997 & 0.9998 & 0.9996 \\
\hline
\end{tabular}

Linearity range is LOQ- $150 \%$ with respect to $1.0 \mathrm{mg} / \mathrm{mL}$ of bortezomib for impurities;

Linearity range is $50-150 \%$ with respect to $1.0 \mathrm{mg} / \mathrm{mL}$ of bortezomib for assay.

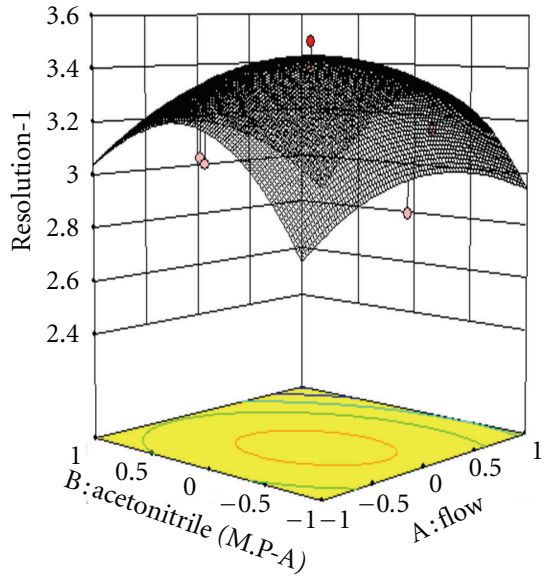

(a)

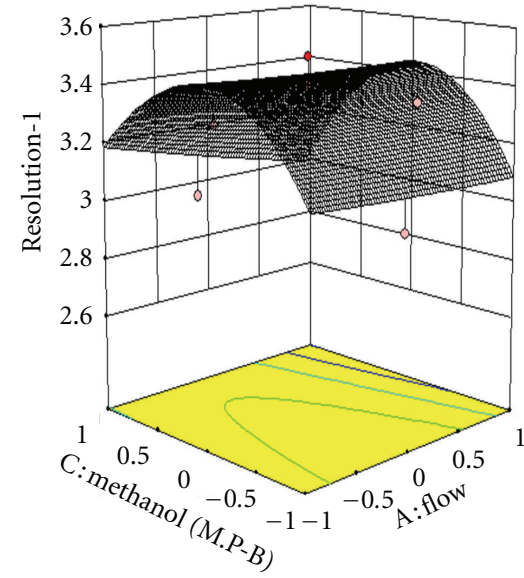

(b)

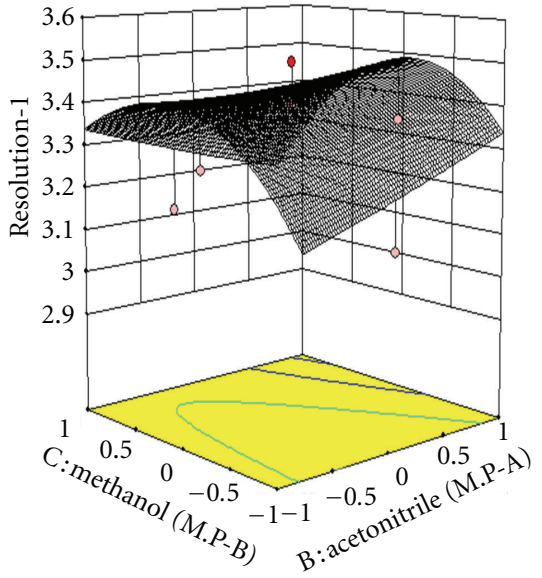

(c)

FIGURE 5: Three-dimensional plot of the response surface for $Y$ (found critical resolution-1 between bortezomib and Imp-C), (a) variation of the response $Y$ as a function of A (flow rate) and B (\% acetonitrile); fixed factor: $\mathrm{C}$ ( $\%$ methanol) $=80 \% \mathrm{v} / \mathrm{v}$, (b) variation of the response $Y$ as a function of A (flow rate) and $\mathrm{C}(\%$ methanol); fixed factor: $\mathrm{B}(\%$ acetonitrile $)=28.5 \% \mathrm{v} / \mathrm{v}$, (c) variation of the response $Y$ as a function

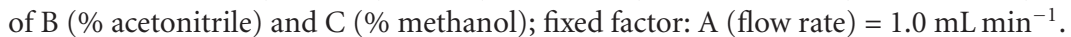

LOQ level was below 10\% RSD. LOD and LOQ established with bortezomib is applicable to unspecified impurities. Recovery at LOQ level for the nine impurities was in the range of 91.1 to $101.7 \%$.

3.2.6. Accuracy. The percentage recovery of bortezomib in bulk samples was ranged from 99.6 to $99.9 \%$. The percentage recovery of impurities in bortezomib samples varied from 94.2 to $107.4 \%$. The LC chromatogram of spiked sample of all nine impurities in bortezomib sample is shown in (Figure 3). The \% recovery values for bortezomib and impurities are presented in Table 5. The percentage recovery and percentage RSD for three preparations shows that this method is accurate for the determination of assay and related substances of bortezomib.

3.2.7. Precision. The \% RSD of assay of bortezomib during assay method precision study was well within $0.4 \%$. The $\%$ RSD of content (\%) of Imp-A, Imp-B, Imp-C, Imp-D, Imp-E, Imp-F, Imp-G, Imp-H, Imp-I in related substance method precision study was within $5 \%$. The $\%$ RSD of assay results obtained in intermediate precision study was within $0.4 \%$, confirming good precision of the method.

3.2.8. Robustness. The experimental domain of the selected variables is reported in Table 1 . The ranges examined were small deviations from the method settings and the corresponding responses in the resolution and recoveries considered $(Y)$ were observed. A three-factor CCD requires 16 experiments, including two replicates of the center point. Standard run and run order generated by Design Expert software are given in Table 6. By using a fitted full quadratic model (1), a response surface regression analysis for each response factor was performed using coded units. Table 7 shows the values calculated for the coefficients and $P$-values ( $P$-value is the probability of the null hypothesis). Using a 5\% significance level, a factor is considered to affect the response if the coefficients differ from zero significantly and the $P$ value $<0.050$ :

$$
\begin{aligned}
Y= & X_{0}+X_{\mathrm{A}} F_{\mathrm{A}}+X_{\mathrm{B}} F_{\mathrm{B}}+X_{\mathrm{C}} F_{\mathrm{C}}+X_{\mathrm{AB}} F_{\mathrm{A}} F_{\mathrm{B}}+X_{\mathrm{AC}} F_{\mathrm{A}} F_{\mathrm{C}} \\
& +X_{\mathrm{BC}} F_{\mathrm{B}} F_{\mathrm{C}}+X_{\mathrm{AA}} F_{\mathrm{AA}}+X_{\mathrm{BB}} F_{\mathrm{BB}}+X_{\mathrm{CC}} F_{\mathrm{CC}}
\end{aligned}
$$




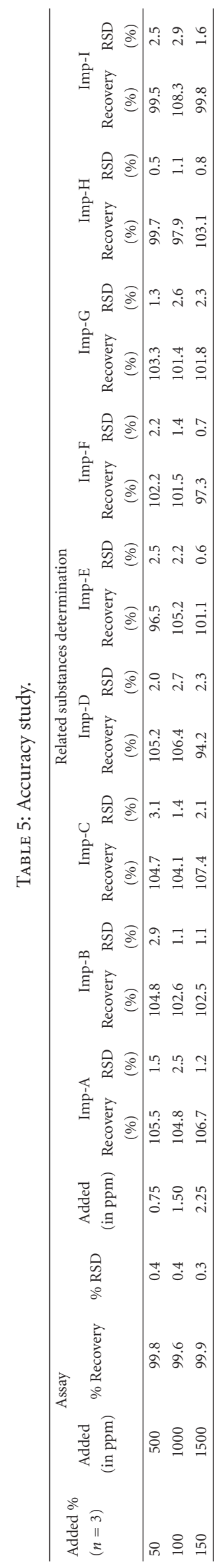


TABLE 6: Standard run, run order, and response obtained for robustness testing.

\begin{tabular}{lccccccc}
\hline Standard & Run & Factor A & Factor B & Factor C & $\begin{array}{c}\text { Resolution-1 } \\
\text { (Bortezomib and Imp-C) }\end{array}$ & $\begin{array}{c}\text { Resolution-2 } \\
\text { (Imp-E and Imp-F) }\end{array}$ & $\begin{array}{c}\% \text { w/w } \\
\text { Assay }\end{array}$ \\
\hline 3 & 1 & -1 & 1 & 1 & 3.0 & 2.3 & 99.3 \\
1 & 2 & 1 & 1 & -1 & 2.9 & 2.3 & 99.1 \\
4 & 3 & -1 & -1 & -1 & 3.1 & 2.4 & 99.3 \\
5 & 4 & 0 & 0 & 0 & 3.5 & 2.6 & 99.9 \\
6 & 5 & 0 & 0 & 0 & 3.4 & 2.5 & 100.1 \\
2 & 6 & 1 & -1 & 1 & 3.0 & 2.2 & 99.2 \\
7 & 7 & 0 & 0 & 0 & 3.5 & 2.5 & 99.9 \\
13 & 8 & 0 & 0 & 1 & 3.2 & 2.4 & 99.5 \\
12 & 9 & 0 & 0 & -1 & 3.4 & 2.3 & 99.6 \\
15 & 10 & 0 & 0 & 0 & 3.4 & 2.6 & 99.8 \\
14 & 11 & 0 & 0 & 0 & 3.5 & 2.5 & 99.9 \\
16 & 12 & 0 & 0 & 0 & 3.5 & 2.6 & 100.1 \\
8 & 13 & -1 & 0 & 0 & 3.1 & 2.5 & 99.4 \\
11 & 14 & 0 & 1 & 0 & 3.0 & 2.4 & 99.6 \\
9 & 15 & 1 & 0 & 0 & 2.8 & 2.5 & 99.4 \\
10 & 16 & 0 & -1 & 0 & 3.2 & 99.8 \\
\hline
\end{tabular}

TABLE 7: Regression coefficients and the associated probability values ( $P$-value) for each response.

\begin{tabular}{lcccccc}
\hline \multirow{2}{*}{ Term } & \multicolumn{2}{c}{ Resolution-1 } & \multicolumn{2}{c}{ Resolution-2 } & \multicolumn{2}{c}{ Bortezomib } \\
& Coeff. & $P$-value & Coeff. & $P$-value & Coeff. & $P$-value \\
\hline Constant & 3.43 & 0 & 2.54 & 0 & 99.92 & 0 \\
Factor A & -0.150 & 0.1549 & -0.100 & 0.0545 & 0.000 & 1.0000 \\
Factor B & -0.100 & 0.3151 & 0.000 & 1.0000 & -0.100 & 0.3763 \\
Factor C & -0.100 & 0.3151 & 0.050 & 0.2668 & -0.050 & 0.6480 \\
$\mathrm{~A} \times$ B & -0.100 & 0.4039 & 0.100 & 0.0968 & -0.075 & 0.5781 \\
$\mathrm{~A} \times \mathrm{C}$ & -0.050 & 0.6677 & 0.000 & 1.0000 & -0.075 & 0.5781 \\
$\mathrm{~B} \times \mathrm{C}$ & -0.100 & 0.4039 & -0.050 & 0.3544 & 0.075 & 0.5781 \\
$\mathrm{~A}^{2}$ & -0.344 & 0.0074 & -0.032 & 0.4038 & -0.413 & 0.0062 \\
$\mathrm{~B}^{2}$ & -0.194 & 0.0575 & -0.032 & 0.4038 & -0.113 & 0.2703 \\
$\mathrm{C}^{2}$ & 0.005 & 0.9477 & -0.182 & 0.0036 & -0.263 & 0.0343 \\
\hline
\end{tabular}

where $Y$ is the experimental response, $X_{0}$ is constant, $X_{x}$ the coefficients of the factors and interactions and $F_{x}$ stands for each factor.

The model was validated by the analysis of variance (ANOVA). The statistical analysis is shown in Table 7.

As shown in Figures 5 and 6, the analysis produces threedimensional graphs by plotting the response model against two of the factors, while the third is held constant at a specified level, usually the proposed optimum.

From Table 7, it can be seen that $P$ values for any of the studied factors are listed. It shows that the method is highly robust for $0.2 \mathrm{~mL} / \mathrm{min}$ flow rate variation, \% acetonitrile variation in the ratio of mobile phase $\mathrm{A}$, and \% methanol variation in the ratio of $\mathrm{B}$.

\section{Conclusion}

A novel, simple, and accurate stability indicating HPLC method for the determination of bortezomib in the presence of degradation products was described for the first time. This method is highly specific for the quantification of degradation products and process-related impurities of bortezomib. The behaviour of bortezomib under various stress conditions was studied and presented. The method was completely validated showing satisfactory data for all the method validation parameters tested. The developed method is stability indicating and can be used for the routine analysis of production samples and also to check the stability of bortezomib samples. 


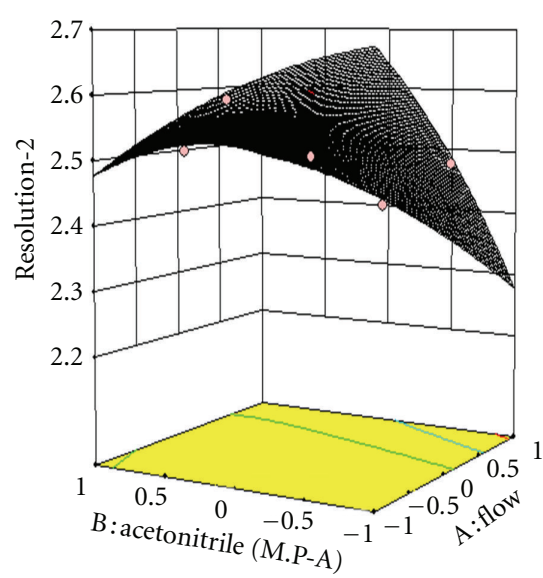

(a)

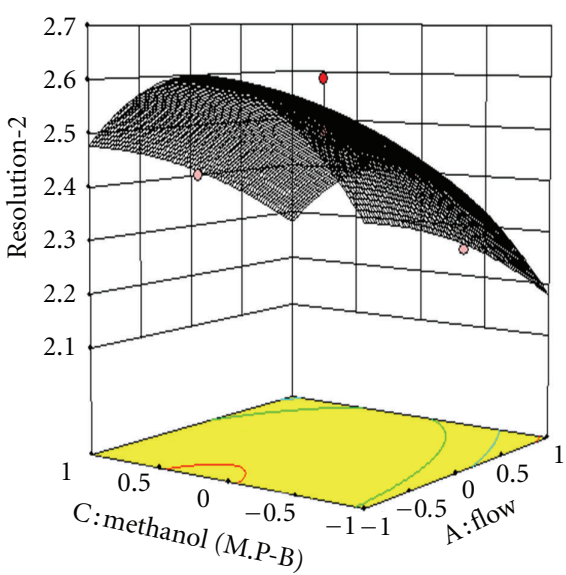

(b)

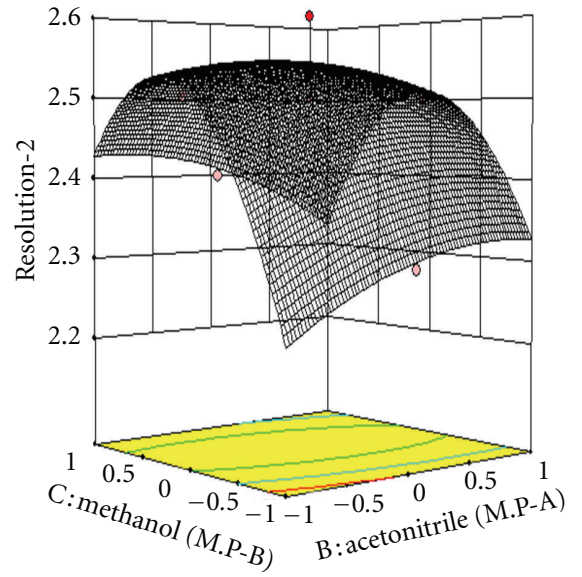

(c)

FIgURE 6: Three-dimensional plot of the response surface for $Y$ (found critical resolution-2 between Imp-E and Imp-F), (a) variation of the response $Y$ as a function of $\mathrm{A}$ (flow rate) and $\mathrm{B}$ (\% acetonitrile); fixed factor: $\mathrm{C}(\%$ methanol) $=80 \% \mathrm{v} / \mathrm{v}$, (b) variation of the response $Y$ as a function of A (flow rate) and C (\% methanol); fixed factor: B (\% acetonitrile) $=28.5 \% \mathrm{v} / \mathrm{v}$, (c) variation of the response $Y$ as a function of $\mathrm{B}\left(\%\right.$ acetonitrile) and $\mathrm{C}(\%$ methanol); fixed factor: $\mathrm{A}$ (flow rate $)=1.0 \mathrm{~mL} \mathrm{~min}^{-1}$.

\section{Acknowledgment}

The authors wish to thank the management of Dr. Reddy's Laboratories Ltd. for supporting this work. There is no conflict of interest in the manuscript.

\section{References}

[1] J. Adams and R. Stein, "Novel Inhibitors of the Proteasome and Their Therapeutic Use in Inflammation," Annual Reports in Medicinal Chemistry, vol. 31, no. C, pp. 279-288, 1996.

[2] J. Adams, "The proteasome: a suitable antineoplastic target," Nature Reviews Cancer, vol. 4, no. 5, pp. 349-360, 2004.

[3] J. Adams, Y. Ma, R. Stein, M. Baevsky, L. Grenier, and L. Plamondon, "Boronic ester and acid compounds, synthesis and uses," 1996, US, 1448.012TW01.

[4] P. G. Richardson, T. Hideshima, and K. C. Anderson, "Bortezomib (PS-341): a novel, first-in-class proteasome inhibitor for the treatment of multiple myeloma and other cancers," Cancer Control, vol. 10, no. 5, pp. 361-369, 2003.

[5] R. J. Snow and W. W. Bachovchin, "Boronic acid inhibitors of dipeptidyl peptidase IV. A new class of immunosuppressive agents," Advances in Medicinal Chemistry, vol. 3, no. C, pp. 149-177, 1995.

[6] European Medicines Agency, "European public assessment report: scientific discussion. The committee for medicinal products for human use," 2004, http://www.emea.eu.int/ humandocs/Humans/EPAR/velcade/velcade.htm.

[7] J. S. Daniels, T. Pekol, J. Labutti et al., "Human metabolism of the proteasome inhibitor bortezomib: identification of circulating metabolites," Drug Metabolism and Disposition, vol. 33, no. 6, pp. 771-777, 2005.

[8] P. André, S. Cisternino, F. Chiadmi et al., "Stability of bortezomib 1-mg/mL solution in plastic syringe and glass vial," Annals of Pharmacotherapy, vol. 39, no. 9, pp. 1462-1466, 2005.

[9] D. D. Jandial, S. Farshchi-Heydari, C. A. Larson, G. I. Elliott, W. J. Wrasidlo, and S. B. Howell, "Enhanced delivery of cisplatin to intraperitoneal ovarian carcinomas mediated by the effects of bortezomib on the human copper transporter 1," Clinical Cancer Research, vol. 15, no. 2, pp. 553-560, 2009.

[10] J. S. Johnston, M. A. Phelps, K. A. Blum et al., "Development and validation of a rapid and sensitive high-performance liquid chromatography-mass spectroscopy assay for determination of 17-(allylamino)-17-demethoxygeldanamycin and 17-(amino)-17-demethoxygeldanamycin in human plasma," Journal of Chromatography B, vol. 871, no. 1, pp. 15-21, 2008.

[11] ICH Q1A(R2), "Stability Testing of New Drug Substances and Products," 2000.

[12] I. C. H. Stability, "Testing of New Drug Substances and Products Q1A (R2)," in Proceedings of the International Conference on Harmonization (IFPMA '03), Geneva, Switzerland, 2003.

[13] United States pharmacopoeia, United States Pharmacopeial Convention, Rockville, Md, USA, 31st edition, 2008.

[14] T. C. Jens and C. T. Rhodes, Drug Stability Principles and Practices, 3rd, Marcel Dekker, New York, NY, USA.

[15] M. Bakshi and S. Singh, "Development of validated stabilityindicating assay methods_critical review," Journal of Pharmaceutical and Biomedical Analysis, vol. 28, no. 6, pp. 1011-1040, 2002.

[16] ICH Q2 (R1), "Validation of Analytical Procedures: Text and Methodology," 2005.

[17] G. A. Shabir, "Validation of high-performance liquid chromatography methods for pharmaceutical analysis: understanding the differences and similarities between validation requirements of the US Food and Drug Administration, the US Pharmacopeia and the International Conference on Harmonization," Journal of Chromatography A, vol. 987, no. 1-2, pp. 57-66, 2003.

[18] M. Ribani, C. B. Grespan Bottoli, C. H. Collins, I. C. S. Fontes Jardim, and L. F. Costa Melo, "Validation for chromatographic and electrophoretic methods," Quimica Nova, vol. 27, no. 5, pp. 771-780, 2004.

[19] Y. Vander Heyden, A. Nijhuis, J. Smeyers-Verbeke, B. G. M. Vandeginste, and D. L. Massart, "Guidance for robustness/ 
ruggedness tests in method validation," Journal of Pharmaceutical and Biomedical Analysis, vol. 24, no. 5-6, pp. 723-753, 2001.

[20] D. K. Lin, "Discussion on papers by Box and Liu, Box, and Myers," Journal of Quality Technology, vol. 31, pp. 61-66, 1999.

[21] K. K. Hockman and D. Berengut, "Design of experiments," Chemical Engineering, vol. 102, pp. 142-148, 1995.

[22] H. Fabre, "Robustness testing in liquid chromatography and capillary electrophoresis," Journal of Pharmaceutical and Biomedical Analysis, vol. 14, pp. 1125-1132, 1996.

[23] B. Singh, R. Kumar, and N. Ahuja, "Optimizing drug delivery systems using systematic "design of experiments." Part I: fundamental aspects," Critical Reviews in Therapeutic Drug Carrier Systems, vol. 22, pp. 27-105, 2004.

[24] S. Pinzauti, P. Gratteri, S. Furlanetto, P. Mura, E. Dreassi, and R. Phan-Tan-Luu, "Experimental design in the development of voltammetric method for the assay of omeprazole," Journal of Pharmaceutical and Biomedical Analysis, vol. 14, no. 8-10, pp. 881-889, 1996.

[25] S. Wu, W. Waugh, and V. J. Stella, "Degradation pathways of a peptide boronic acid derivative, 2-Pyz-(CO)-Phe-Leu$\mathrm{B}(\mathrm{OH}) 2$," Journal of Pharmaceutical Sciences, vol. 89, pp. 758$765,2000$. 


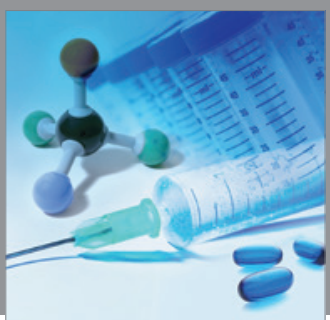

International Journal of

Medicinal Chemistry

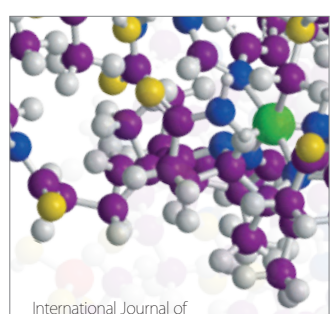

Carbohydrate Chemistry

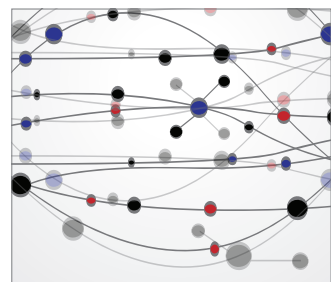

The Scientific World Journal
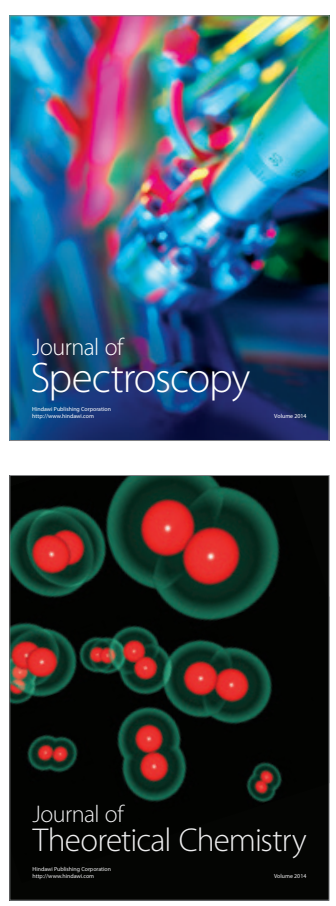
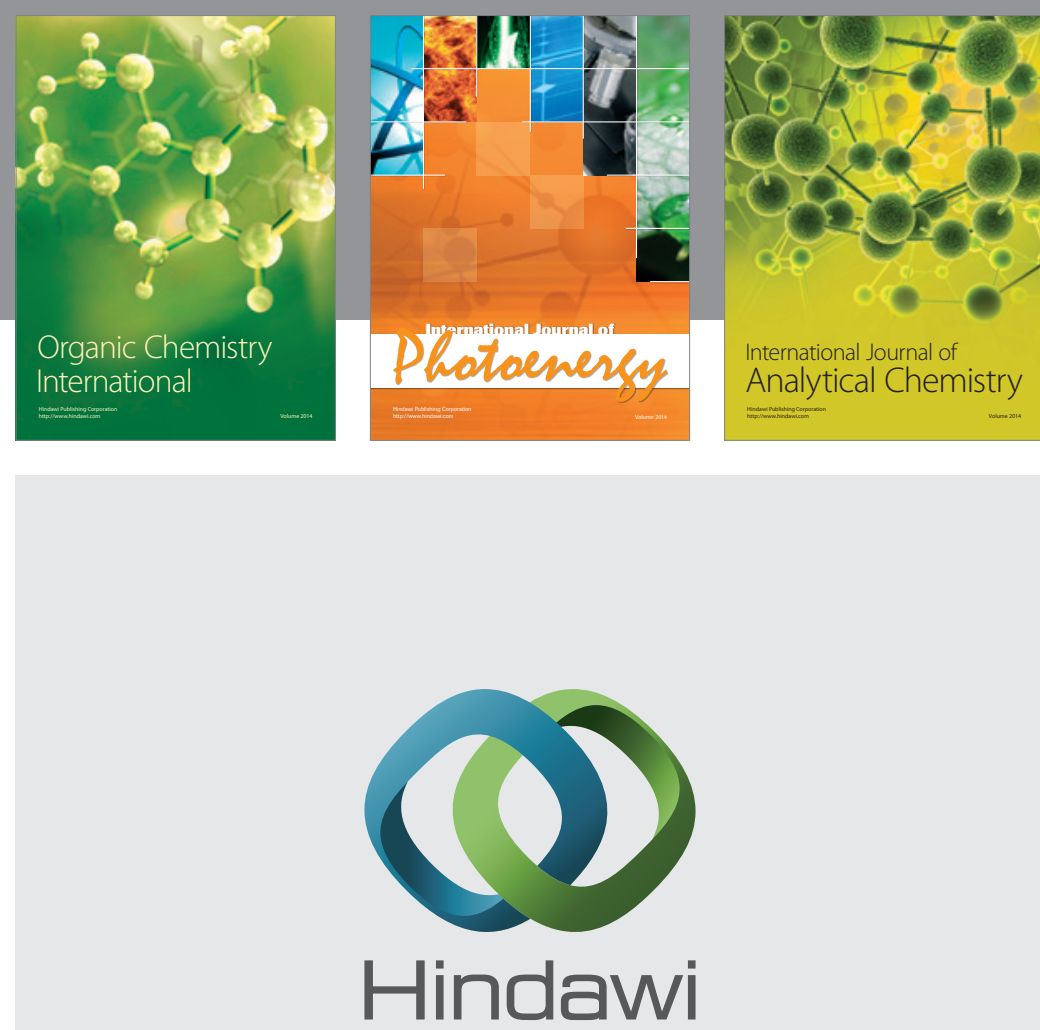

Submit your manuscripts at

http://www.hindawi.com
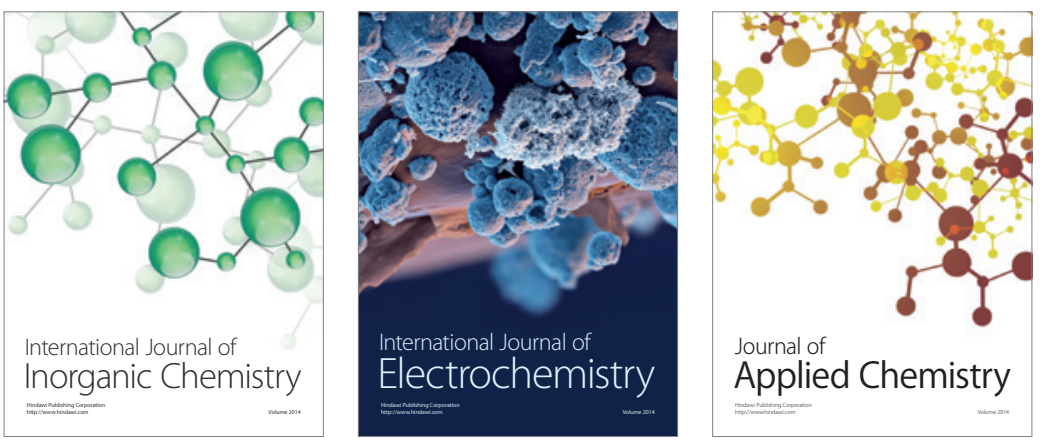

Journal of

Applied Chemistry
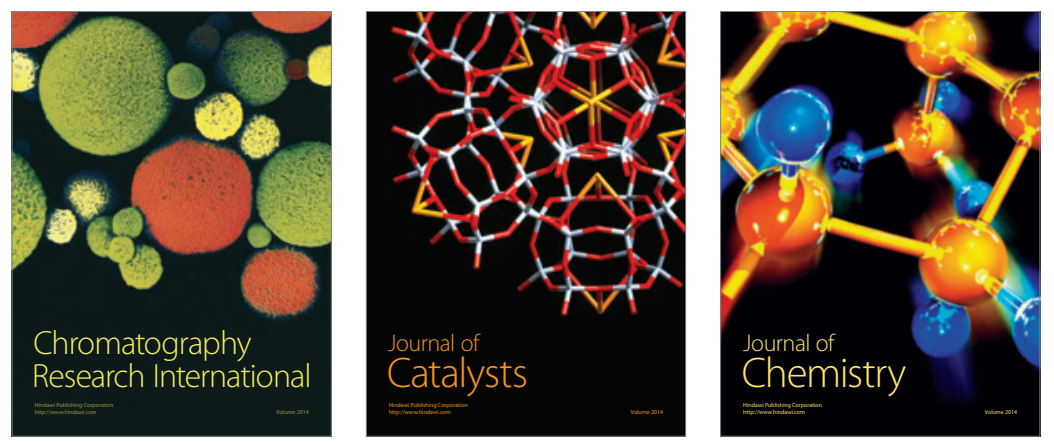
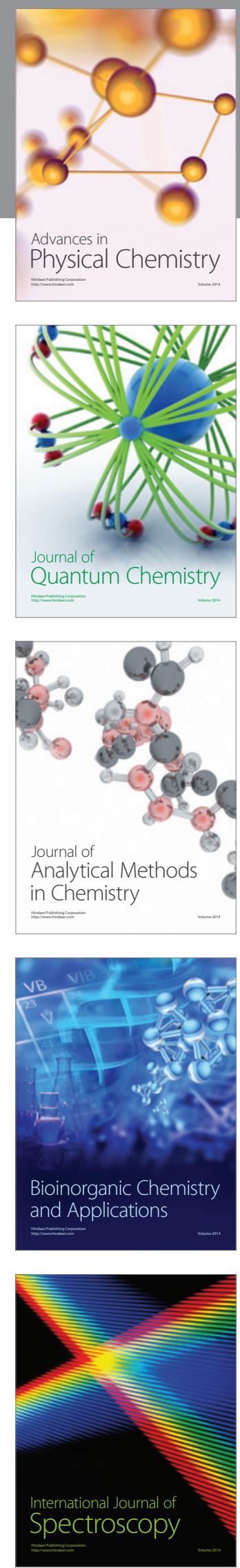